\title{
Conditions for Innovation: Insights from a multi-case study
}

\author{
Magnus Wiktorsson', Margareta Groth²
}

\begin{abstract}
The paper is based on a multiple-case study of conditions for product-based innovations. Key actors from 18 cases were interviewed concerning the specific character of the innovation process, its parts and phases, with a focus on the realization phase. The cases are analyzed and discussed on the basis of an experience-based framework with seven specific components. In addition, the data are illustrated and discussed by more general themes of successful and unsuccessful innovation processes. It is concluded that the components of the used framework are necessary but individually not sufficient to maintain a continuous friction-free innovation process. The dynamics of the innovation processes are well illustrated by the framework.
\end{abstract}

Keywords: Multiple case study; interview; innovation process; innovation conditions.

\footnotetext{
' Mälardalen University, School of Innovation, Design and Engineering, Box 325, SE-63I 05 Eskilstuna, Sweden. Phone: +46 (0)I6 I5 3229. Email: magnus.wiktorsson@mdh.se (corresponding author)

2 VINNOVA, the Swedish Governmental Agency for Innovation Systems. Manufacturing and Materials Department.

SE-I0I 58 Stockholm, Sweden. Phone: +46 (0)8 47330 00. Email: margareta.groth@vinnova.se
} 
J. Technol. Manag. Innov. 20I I,Volume 6, Issue 2

\section{Introduction}

Disruptive innovation processes have in many aspects been thoroughly analyzed, but are still something of an enigma on a micro level. It is an area inhabited by many kinds of actors; scientists, entrepreneurs, companies, financiers, customer, inventors, business angels etc. Product and business innovation can also emerge in a vast number of environments. Still, the innovation process proceeds through these actors and environments and if we better can understand the conditions for this innovation management and process, it might be able to capitalize on the investments for nurturing innovation more effectively.

Over the last decades a number of approaches have been used for describing and explaining success and failure of innovative behavior. In its simplest form, the neoclassical economic school argued for growth by introducing more productive technologies raising the technology coefficient or by capital accumulation. Supply and demand was in focus. Schumpeter's original theory of innovation highlighted however the 'creative destruction' of innovation, where innovation challenges the existing conditions and redefines the space in which innovation take place (Schumpeter, 1934). Another central theme in the Schumpeterian innovation school is the cause-effect reasoning from micro to macro. Actions and activities on a micro level give impact on a macro level, while the opposite not necessary is true. The entrepreneur is central in Schumpeter's view on innovation.

Following this reasoning, a number of models have been developed for describing innovation. The explanatory linear innovation models dominantfrom the 1950s to the mid 1970's have been replaced by integrated and networked models. Rothwell (1994) describes five generations of innovation models where the later generations of innovation models that have evolved in the last three decades are increasingly more complex and sophisticated, considering more and more elements. Abernathy and Clark (1985) developed a model focusing on the discontinuities in innovation. The work of Christensen (1997) drew attention to cases where the market was the effective trigger point. More recent work by Christensen and Raynor (2003) have extended this market based approach to deal with two dimensions of renewal, one where innovation occurs as a consequence of performance measures competing against existing markets, and one where it competes against non-consumption.
Radically new products and services can occur in hightechnology niches of pioneering innovations (Utterback and Acee, 2005, Deeds et al., 2000), or in lowertechnology niches of new configurations of existing technologies (Schmidt, 2004). Chesborough (2003) discusses the move towards 'open innovation' where links and connections become as important as the actual production and ownership of knowledge. In recent years, approaches have been presented synthesizing technological, organizational and commercial aspects of the innovation process (Tidd and Bessant 2009). Conway and Steward (2006) examine innovation as a managerial, social, political, and emotional process. Openness, context dependence and non-linearity are viewed as central features in modern models used to describe and influence innovation, i.e. the process of generating new products and methods (Marinova and Phillimore 2003).

From these general models of innovation, recently published literature have presented various success factors as key determinants of disruptive innovation. In a conceptual article, Colarelli O'Connor (2008) presents a framework composed of seven elements, together forming a management system (rather than a process-based approach) for nurturing radical innovation. Other structures presenting key challenges with developing organizational capabilities for disruptive and dynamic innovation are presented by $e$ g Eisenhardt and Martin (2000) and Teece (2007). A complementary approach to the success factor based models is presented by Assink (2006) examining inhibitors or barriers of disruptive innovation. The analysis regards the barriers, as well as their interrelationship and interdependence, as major factors that limit a firm's capability for disruptive innovation.

However, presented models in innovation management literature are to a large extent descriptive on a macro or mezo level. The level of generalization and the explanatory ambitions are high. We have found a lack of descriptive models on a true micro level, from an idea or case horizon. From a micro perspective, literatures of innovation, psychology and sociology focus e $g$ individual creativity as a key enabler for innovation. As Griffin et al (2009) also reports, there is a gap in our understanding between individual creativity on a micro level and organizations' ability to create and commercialize innovations on a macro or mezo level. 
This paper is the result of a multiple-case (Yin, 1994) research study where 18 cases were in-depth studied through interviews and written material. This paper hopes to, within the context of these more overarching models, contribute to filling this gap by empirical findings and analyze central conditions for innovation, based on real innovation cases. The cases are analyzed on the basis of a descriptive and experience-based framework, analyzing the components of the innovation process.

\section{Methodology: the study and the analysis framework}

The study covers the innovation process from an idea to a commercialized product, or until the process has been intercepted - through the phases of Select and Capture, using the terms coined by Tidd and Bessant (2009). We do not study specifically the process before the origin of the idea or how creative environments are to be created (the Search phase), or the latter phase of knowledge and profit gathering (the Capture phase).

Innovation is a broad term concerning 'the implementation of a new or significantly improved product (good or service), or process, a new marketing method, or a new organizational method in business practices, workplace organization or external relations' (OECD, 2005). This study has however primarily been targeted against product innovation (goods or service) where the final exploitation lies within the manufacturing or energy sector.

\section{Sample}

I8 cases were chosen to illustrate a broad spectrum of environments and represent success cases as well as failures. In most cases, the study was conducted during the development phase of the idea. The cases were selected from a replication logic perspective in dialogue with contacts in industry and regional innovation support organizations. Each case was selected due to either a literal replication, predicting similar results as other cases, or due to a theoretical replication, where results will be in contrast to other cases but for predictable reasons. The main logic of conducting the multiple-case study was to build theoretical replication, where different cases build a total knowledge mass of critical aspects. Thus the majority of the cases were selected to complement each other. The cases were from various origins and focusing on various business areas as illustrated in Figure I. The 18 cases were complemented with interview studies of three large companies' innovation processes, also indicated in Figure I. 


\begin{tabular}{|c|c|c|c|c|c|c|}
\hline \multirow{2}{*}{ 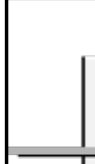 } & \multirow{2}{*}{ Sectors } & \multicolumn{5}{|c|}{ Source of idea } \\
\hline & & Academic & Institute & $\begin{array}{l}\text { Large } \\
\text { company }\end{array}$ & SME & $\begin{array}{l}\text { Free } \\
\text { actor }\end{array}$ \\
\hline \multirow{6}{*}{ 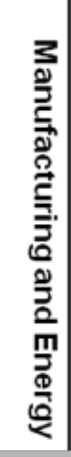 } & $\begin{array}{l}\text { Aerospace / } \\
\text { defence }\end{array}$ & & & & & \\
\hline & Auto/machine & & & & & \\
\hline & Energy tech & & & & & \\
\hline & Energy service & & & & & \\
\hline & Pulp \& Paper & & & & & \\
\hline & Other sectors & & & & & (11) \\
\hline \multirow{3}{*}{ 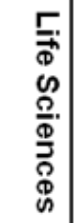 } & Biotech & & & & & \\
\hline & Farmaceutical & & & & & \\
\hline & Med tech & & & & & \\
\hline \multirow{3}{*}{$\begin{array}{l}\overline{7} \\
\overline{-1} \\
\frac{\Phi}{\Phi} \\
0 \\
\Xi\end{array}$} & Data & & & & & \\
\hline & TelCo & & & & & \\
\hline & Electronics & & & & & \\
\hline \multirow{2}{*}{\multicolumn{7}{|c|}{$\begin{array}{l}\text { 1. Effective combustion engine from free agent } \\
\text { 2. Particle purification in partnership }\end{array}$}} \\
\hline & & & & & & \\
\hline 3. & Long-term univer & research in & he energy & rea leads $\mathrm{t}$ & & \\
\hline \multicolumn{7}{|c|}{ 4. University research with customer application n } \\
\hline \multicolumn{7}{|c|}{ 5. Research results became biotech company } \\
\hline \multicolumn{7}{|c|}{ 6. Service idea within the energy sector } \\
\hline \multicolumn{7}{|c|}{ 7. Consortium development of raw material storage } \\
\hline \multicolumn{7}{|c|}{ 8. SME is created around energy reservation } \\
\hline \multicolumn{7}{|c|}{ 9. IT within the energy sector } \\
\hline \multicolumn{7}{|c|}{ 10. Sensor technology creates companies } \\
\hline \multirow{3}{*}{\multicolumn{7}{|c|}{$\begin{array}{l}\text { 11. The inventor's idea on consumer product is transferred to own companies } \\
\text { 12. Research institute create industrial projects on the basis of research results } \\
\text { 13. Companies created on the basis of idea regarding automation and efficiency } \\
\text { improvement }\end{array}$}} \\
\hline & & & & & & \\
\hline & & & & & & \\
\hline \multicolumn{7}{|c|}{ 14. Switch idea meets obstacles in the big company } \\
\hline \multicolumn{7}{|c|}{ 15. Security radar on the basis of earlier product idea } \\
\hline \multicolumn{7}{|c|}{ 16. Process technology within large companies } \\
\hline \multicolumn{7}{|c|}{ 17. Composites and it's processing } \\
\hline \multicolumn{7}{|c|}{ 18. Car radar on the basis of technology know-how } \\
\hline
\end{tabular}

Figure I. The 18 cases (numbered above). In addition, three studies concerned general innovation processes in large multi-national companies (not numbered). 


\section{Analysis framework}

In order to analyze the cases we used an experiencebased framework of factors that is considered important for innovation success. By this study on a micro-level, critical issues are raised on the basis of actual experiences (experiences that in themselves cannot be questioned). A case study series gives however never bases for a statistical generalization but relies on observation and analysis as the basis for conclusions (Yin, 1994). The used framework of innovation process components is illustrated in Figure 2 and described in detail in the following.

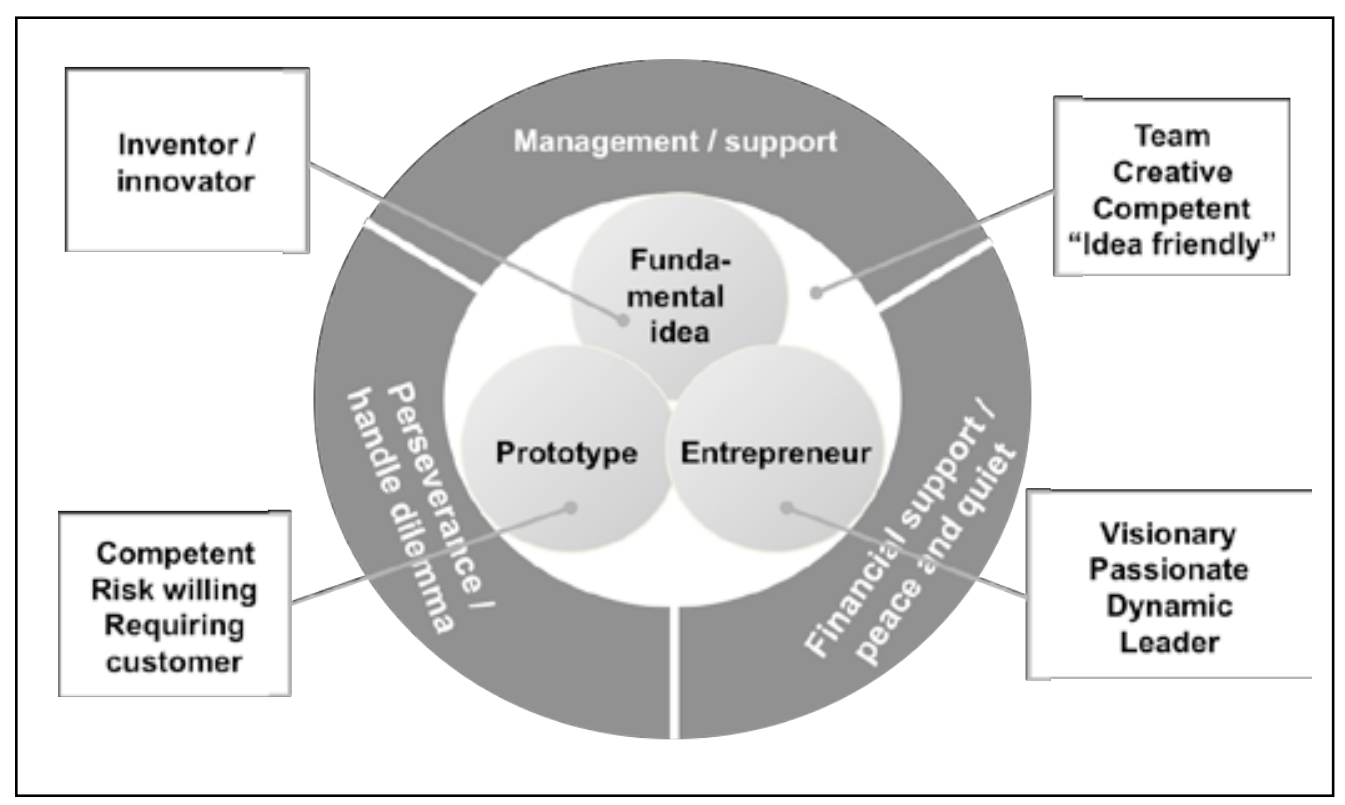

Figure 2. Illustrating the analysis framework and its components.

Fundamental idea: The fundamental idea constitutes the technical and commercial hypothesis that is to be developed. It can have its origin in technology or market, but must always contain both parts. An inventor or innovator is the most common initiator of the process.

Entrepreneur: The entrepreneur runs the work with realizing the carrying idea. Typical abilities of an entrepreneur are to see the fundamental idea's commercial possibilities and to be a visionary and leading a team.

Prototype/demanding customer: The prototype plays a role in the verification of the idea. By the prototype the technical and commercial relevance of the idea is secured. An important quality of the prototype is that it is developed with a skilled, risk willing and demanding customer.
Team: Several persons need to attend the creative process. The team contributes with competence, resources and constitutes a social system with common values regarding the fundamental idea.

Management/support: The team and the entrepreneur needs to relate itself to a guiding and supporting context, e.g. mentors, board, sponsors, in order to have the energy for the hard work of developing and verifying the idea.

Financial support / peace and quiet essential for work: The financial support does not only give resources, but also peace and quiet for the entrepreneur and the team.

Perseverance and handle dilemma: An important quality in the organization is to strategically and tactically handle the obstacles and obstruction that the idea raises: perseverance is required to handle these dilemmas. These obstructions can be both internally within a company as well as external market obstructions. 


\section{Interview structure}

The data collection was conducted through I-3 interviews for each case, with informants participating as inventor, entrepreneurs or project managers. In total was 30 informants interviewed by four persons over two months. The informants were informed by the topics of the questions and asked to in advance review and sketch the process for four key aspects of the innovation process:

- The idea's development

- Team composition: inventor, entrepreneur, team and management

- Prototype and other verification of customer requirements -The financing's development

Each interview lasted for 2-3 hours. Information was collected in an open-interview manner regarding the seven components of the framework by walking through the above four aspects of the innovation process. Correlations between aspects were also documented as well as good/poor experiences.

\section{Analysis}

The interviews were transcribed for analysis. Since multiple informants were interviewed for each case, a more complete picture of all aspects of the innovation process could be formed. The documentation concerning respective case described both the process where the idea was developed, as well as a number of experiences regarding good and less good functionality and important and less important aspects. The transcripts were content analyzed by individuals in the research team to search for common themes. The team met and reviewed their individual findings, verifying the possibility of structuring the process according to the seven components (Figure 2), as well as identifying general themes (Crewell, 2009) relating to challenges in the innovation processes that appeared throughout the cases. The process thus included both an affinity charting process where findings were mapped into the a priori known seven components of the innovation process, as well as a qualitative cluster analysis (Charmaz, 2006) where general themes were formed in a bottom-up manner by the team.

\section{Result presentation: the components of the innovation process}

The observations from the cases were initially structured by the seven basis components in the analysis framework.

\section{Fundamental idea}

The fundamental idea for the cases, are driven from the two dimensions technology and market according to Figure 4 . The majority of the cases concentrate on being innovative either within technology or market. It is a few that is innovative in both dimensions concurrently - the most risky strategy in the Ansoff matrix.

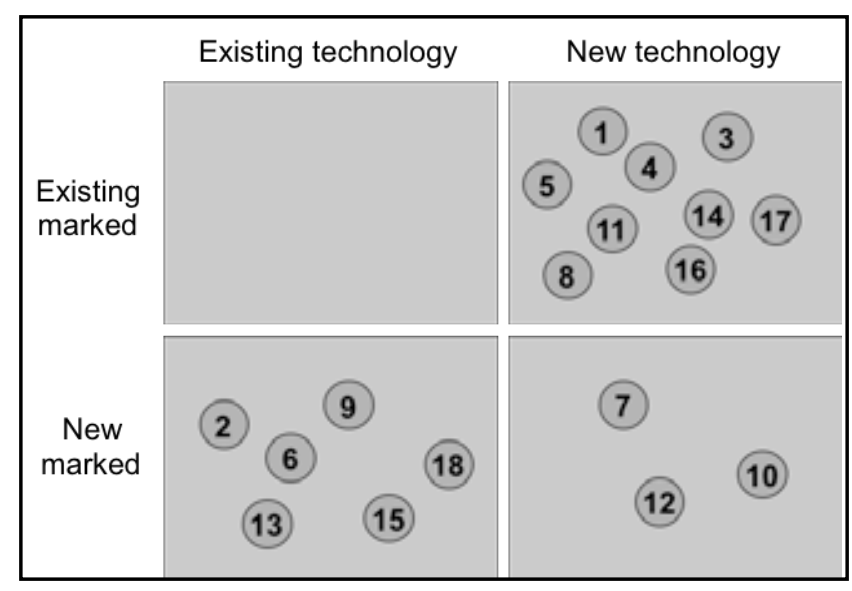

Figure 4. The fundamental idea's focus on technology or market in the cases.

The fundamental idea is refined during the entire innovation process. The innovation process could be described as a hypothesis test of the fundamental idea, which constantly is developed and modified. This development goes from relatively coarse description, technical and economic, to a sophisticated business concept. We conclude however that the fundamental idea can have two typical end objectives: to be incorporated as product launch in an existing business concept or to be developed to a complete business concept, as illustrated in Figure 5. 


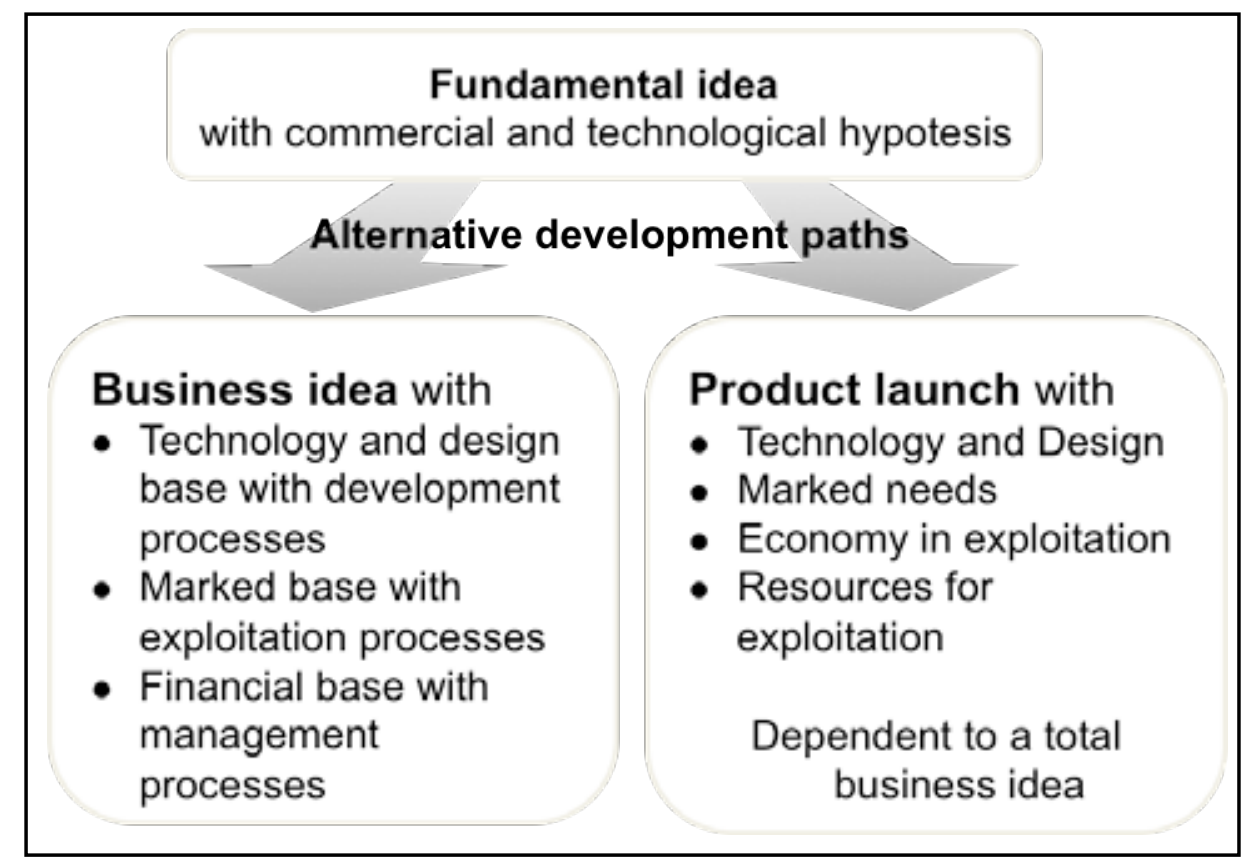

Figure 5. The fundamental idea's alternative development roads: creating a new business concept within the framework of a new formed company, or as a product launch within an overall business concept in an existing company.

These two end objective obviously put entirely different requirements on the fundamental idea's development. Cases very early in their development, as cases I, 4 and 8 , are still to choose strategy. The entrepreneur in case I expressed this in discussing a future exploitation: "There are three paths for our continuation: Make a commitment to a global supplier; to apply for external financing and run on alone; or to link to a partner with an existing end customer segment." In this context, it is also important to realize differences in required time and resources. An idea that will be developed to a complete business concept requires considerably more time, competence and resources in order to succeed. Also ideas that we seen are new within both of the two dimensions technology and market (Figure 4), takes longer time. Still, we have seen cases where ideas are developed and established quicker. Here we find e $g$ ideas that rationalize existing processes.

Illustrative examples on the different origin of ideas are case I, 2 and 3. In case I the fundamental idea was "technology driven" without a clear view of the future business logic. Despite this, the technical focus continued during the process. The idea came from a 'free actor' on the basis of a genuine technical interest. The case represents the typical case when a technical interested inventor through careful blueprints and calculations apply for patents and goes long in its endeavor to verify the idea on a theoretical level. The natural next step for this inventor was to develop a technical prototype on the basis of his own results. The commercial part of the idea was seen as securing financing for creating the prototype. Due to the big investments required for the prototype, the inventor teamed with an entrepreneur that earlier had supported in innovation processes. This person should create and manage customer relationships and to develop the commercial part of the idea. In this case, the idea was far from a final commercial idea.

In case 2 the idea concerning particle purification arose in a meeting between a bigger company's developer and a potential customer. The customer asked if the unique technology could be used in a new application. The developer saw the potential and developed an operational prototype in cooperation with the customer's developer, but without the highest management's direct awareness. Although the customer was involved, the commercial part of the idea was unclear due to unknown production costs. The marked potential was also depended on anticipated 
regulations and subventions. When this idea was brought to the management's attention, the idea was considered as too far from the overall business idea. A discussion was initiated with a company with experience from this specific market. The innovation process was an example on a sophisticated business concept argument, leading to a resolute and for the innovation favorable action.

Case 3 was as case I technology driven. The market did not really exist, but hopes were on that it would arise through state subventions. The market idea was in that sense 'speculative'. We got also a strong impression of that the group's own believe to the idea was weak and can therefore almost be said to stand as examples of an ostensive idea. It is not a question of 'ill will' or enticing information, but by formulating a fundamental idea as an innovative opportunity, being able to finance continued research and technology development.

\section{Entrepreneur}

The entrepreneur's role in the innovation process is central. I many of the cases we have observed technically very skilled persons, typically inventors, needing to incorporate an entrepreneur working with the exploitation and management of the idea. In a small fully owned company, started around the innovation, the entire business idea is to be managed (e.g. case 8), while in a large company "only" project management/technology dissemination is managed (e.g. case 7). Hereby, quite large differences in the role of the entrepreneur were observed. Following list illustrates the diverse backgrounds of the persons that had the role of the entrepreneur in the cases:

- Entrepreneurs with/without leadership experience.

- Inventor with/without business experience.

- Externally engaged entrepreneurs

- Project managers in large companies

- Business angels (see section on Management/support below)

Case 9 concern an IT application that was verified in an institute (acting as customer) and now aiming on being launched on a new market. The company was started by two software knowledgeable persons with the aid of a business angel, acting as entrepreneur. In order to commercialize the idea on a new market, a CEO was engaged acting as entrepreneur and running the exploitation of the fundamental idea. A similar process occurred in case II, where the inventors handed over the entrepreneur role to the CEO in a new company. The inventors had an owner share, but not as majority owner.
The following abilities at the entrepreneur have been mentioned during the interviews as desirable:

- Identify commercialization possibilities

- An understanding of the technology and design

- A driving spirit

- Networking and social ability

- Leadership abilities

- Perceptive and flexible

Though these abilities are covered in the entrepreneur role, it is not always one person that is the entrepreneur; it can be several persons interacting in an entrepreneur team. Moreover, the entrepreneur's abilities vary over time. In early phases, we have seen technology based entrepreneurs drive the idea, later complemented with customer and market focused persons.

In case I, the inventor recruited a person for the entrepreneur role. However, the inventor retained the control over the process and the engaged person got a secondary role working with market and customer development. This weakness appeared as the commercial idea was not developed properly.

In one large company case we have also seen how a project manager became responsible for the exploitation of a fundamental idea based on existing technology for a new market. The deficiency was expressed by the lack of a true driving spirit. However, it seems that a person in the company head management had put a lot of prestige in the project and can be said to be the true driving spirit, without being centrally positioned in the project or influencing the project continuously. This raises the question if the entrepreneurial role is possible to delegate.

Also the case with the research institute that launches a quality assurance methodology in case 12, indicate deficiencies in the entrepreneur role. To launch a product that may be classified as new in terms of both technology and market are challenging and requires good business abilities.

In one case with origin in the academic world it was quite clear that the entrepreneur did not have for intention to achieve an industrial effect of bigger dignity. Rather, the fundamental idea's exploitation concerned strengthening the activity's academic base. The entrepreneur was in a conflict situation between developing knowledge for qualification within the academic world or to exploit the business idea (without disseminating knowledge of it in the academic world). 


\section{Prototype through risk willing, demanding customer}

The idea's technical and commercial relevance is verified through a demanding market representative, often one or many customers. Requirement setting is found critical for a successful innovation process.

In cases I and 3 the team worked alone with an idea or general view of the market needs and had no customer involvement. The reason was that the customer needs were thought of as very clear. A more fuel efficient combustion engine should of course be interesting, as well as a more environmentally friendly energy technology, all other equal. We see nevertheless that these cases had difficultly to reach the market, illustrating that an absence of a customer prototype leads to a problematic implementation. The problem is not the absence of a prototype in itself, but the absence of a demanding customer that can describe the properties that make the product attractive on the market.

Case 4 contrasted to the above cases. The university's near contact with the market/customer made it in this case possible to verify the technical and commercial requirements of the researcher's earlier work. Notable is also that this case was initiated by the customer. There was a real customer need as base and it was possible to develop a successful prototype together with the customer. Cases 7 and 16 were similar to case 4 by also being initiated by a customer. However, in these cases the customer also developed the idea. Most analyzed cases have their origin in technical developments. Notable is however that several of these do not succeed due to the lack of a proper customer involvement.

It has in certain cases shown that working with a customer is not always sufficient and desirable. In case 10 the deep customer involvement led to an unfavorable development. The customer did in this case not represent the intended market. The application and the concept became unique for the customer's specific needs.

In case 2 the team secured input from a broader market by involving all possible customers. A pair of the potential customers was more directly involved and the work was continuously balanced with the others.
Case II targeted a mass marked. The customer was assumed to put great value in the product if it showed to meet certain good properties. These properties were estimated by a professional user, of course not being able to with full confidence speak for a mass market. By this mass marked focus, the team was referred to market tests of various kinds and selling strategies with elements of endorsement.

We also observed the phenomenon 'risk customer', i e when the customer is participating in the innovation process in itself, such as in case 9. In this case, the customer was a governmental authority securing an offset sufficiently large for the small supplier and also becoming a good reference. In conclusion, has the studied cases that are developed together with a demanding and risk willing market representative, secured a better innovation process.

\section{Team}

In order to have a functional team that pursue the idea, two fundamental aspects have been observed: to have a common objective of the idea and having complementary roles and competence that are required.

In cases 3 and 4 a conflict was observed between the academic research environment and the company commercializing the idea, creating some tension and disturbance to the group. The researchers wanted to publish their results and while the owners to the company wanted to keep the results and commercializing them. Another example is case 10 where the issue of whether to become a system integrator or product vendor was discussed. These strategic discussions consumed energy and inhibited the innovation process. A third example on conflicting objectives is case II where the core team had different agendas with the idea: to build a company around the idea or sell the idea to an existing company. The result became neither. First when a more professional team with a common agenda took care of the idea, the process was pursued.

Regarding the composition of the team, case II made great progress once a more professional team took over. The team consisted of a number of different competences and roles that apart from good management covered market, public relations, technology, design and financing. By tying competence through shares by offset issues and joint ownership, the company managed to attract necessary abilities. 
In case 2 the idea was regarded as lying outside the companies' business concept and competence area. A partner that could allocate knowledge on technology and market was successfully involved in this case. Case 6 shows the same good behavior in, as needs arise, involving necessary competence - in this case competence on service sales and internationalization but also persons well established in the business sector, creating legitimacy for the idea.

In many cases, the team composition was more aimed at solving the technical problems than developing an attractive offering. The crucial business competence is missing in these cases. If the team does not have the ability to drive the idea to a commercial viable idea or not even being able to assess the potential of the idea, a lot of resources are wasted. We conclude that the team composition in the successful cases reflects the critical competences in the intended business idea.

Other team based mechanisms that were important was observed in the cases 5, 7 and 8. Here the processes met considerable obstacles, in one case the idea fell entirely, in another the company went in bankruptcy and in the third case key partners left. However, in all three cases the processes could proceed and more or less being reborn by the core team, due to the strength in the team.

It is clear that the team in the successful cases develops, within itself, very strong links. It is the team, including the entrepreneur, which will overcome the obstruction from the environment. The team forms a social system for those included in the innovation process.

\section{Management and support}

In several cases, the interviewed entrepreneur/intrapreneur emphasizes the support provided by external management, as board, mentors, coaches, sponsors etc. Cases 2 and 7 are good examples on how the management in a large company supports a project and the team by giving resources and promoting the project internally and externally.

In one of the cases there was a conflict between the entrepreneur and the supporting management. The entrepreneur expressed a disappointment regarding the management's (in this case the board of the new company) competence. The conflict was explicable, but the lack of support was negative for the entrepreneur.
An important phenomenon that appeared in some cases was the business angels. A business angel is a person that with own money intervenes in the innovation process, partly with financing but also as a mentor, coach and stakeholder. The role is changed during the process and contributes with competence, experience and support, apart from financing. Thus, the business angel intervenes in several of the seven components in the analysis framework. In case 9 a business angel assisted the company during its entire creation and forming, approximately five years. The financial aid was after five years a smaller part, the important part was the support for the entrepreneur and CEO. The business angel's good abilities, in contrast to other external financiers, is the vicinity to the activity, the contacts within the business sector, the legitimacy given to the company and in this case the expertise within the area. In case 8 the entrepreneur also describes the great value the business angel gave during the first years of company creation.

\section{Financial aid for peace and quiet}

Throughout the study we have observed the differences between securing financial support for ideas developed in internal contexts (within existing companies) and for ideas in external contexts (as new created companies). Cases 2 and 14 are good examples on how bigger companies on lower level in the organization give time to develop an idea. In these cases the financing was truly giving 'peace and quiet'. This time and resources is a form of early 'seed financing' the larger companies can allow. When the work later on was intercepted on higher level (as happened in both cases), "skunk work" is a possibility in a larger company, i e work on an idea without the management's approval. The "slack" in the company is used as an initial and important financing source in innovation processes' early phases. The financing decisions were in these cases passive and not expressed.

For new started companies, the work with assuring financial aid can be a considerable task. It was expressed to be specifically difficult to get support in early phases. In Case II the entrepreneur devoted a lot of time to assure financing and to communicate with financiers. This was considered by the entrepreneur to be a big obstacle for the work that was considered as most important to verify the idea from a cost and market perspective. A mechanism that this company specially mentions as important is shares by offset issues. Suppliers has been able 
to work with the company and converted these efforts into shares of the company. This has partly financed the business, but also created commitments from all parties creating an inter-organizational team.

The cases 6 and 8 describe consultancy work as a way for new-starters to develop their idea without capital. In both cases the entrepreneur and its team have worked with consultancy services within the area that the idea concerns, while developing the idea. This gives a financial base for developing the idea, but also valuable contacts and sector experience. It also builds a close interaction and trust with a potential customer. The negative side, which also was expressed in both cases, is that focus was moved away from the work of exploiting the fundamental idea.

We have also observed some unsound phenomena. In one case the big company had an inability to intercept the innovation process. When partner companies and potential customers left in several rounds, the company nevertheless continued developing and hoped for the big breakthrough. At the end the company realized facts and tried to sell the idea. Also ideas from academic environments have been run years after years without real market results. The phenomenon of overfeeding a process with financing without real follow-up and milestones has been observed in cases such as 4,15 and 18 .
In case 5 a private risk capitalist committed to a long-term financing for 3 years, but the money portioned out in 6 months doses with revision and reconciliation between each phase. The financier was in this case also actively participating in the innovation process as a business angel.

\section{Perseverance and handling dilemma}

Case 14 is an example on internal obstructions. In this case, the idea was intercepted at the top management. The work was carried on with the local management's support and after an analysis of the problem, a strategy was developed. The process was deliberately complemented with a demanding customer. Local team and support was in this big company the key for perseverance.

In case II the company worked for a couple of years to get their product approved in a rule committee, representing a considerable market obstacle. In this case, it was through tactic and strategic competence in the supporting groups that a number of very difficult situations could be handled. A key question emphasized in several of the cases is what obstruction the idea will meet on the journey to a commercial product. For ideas created within an existing company, the type of obstruction depends on to what extent the new idea challenges today's products or markets according to Figure 6.

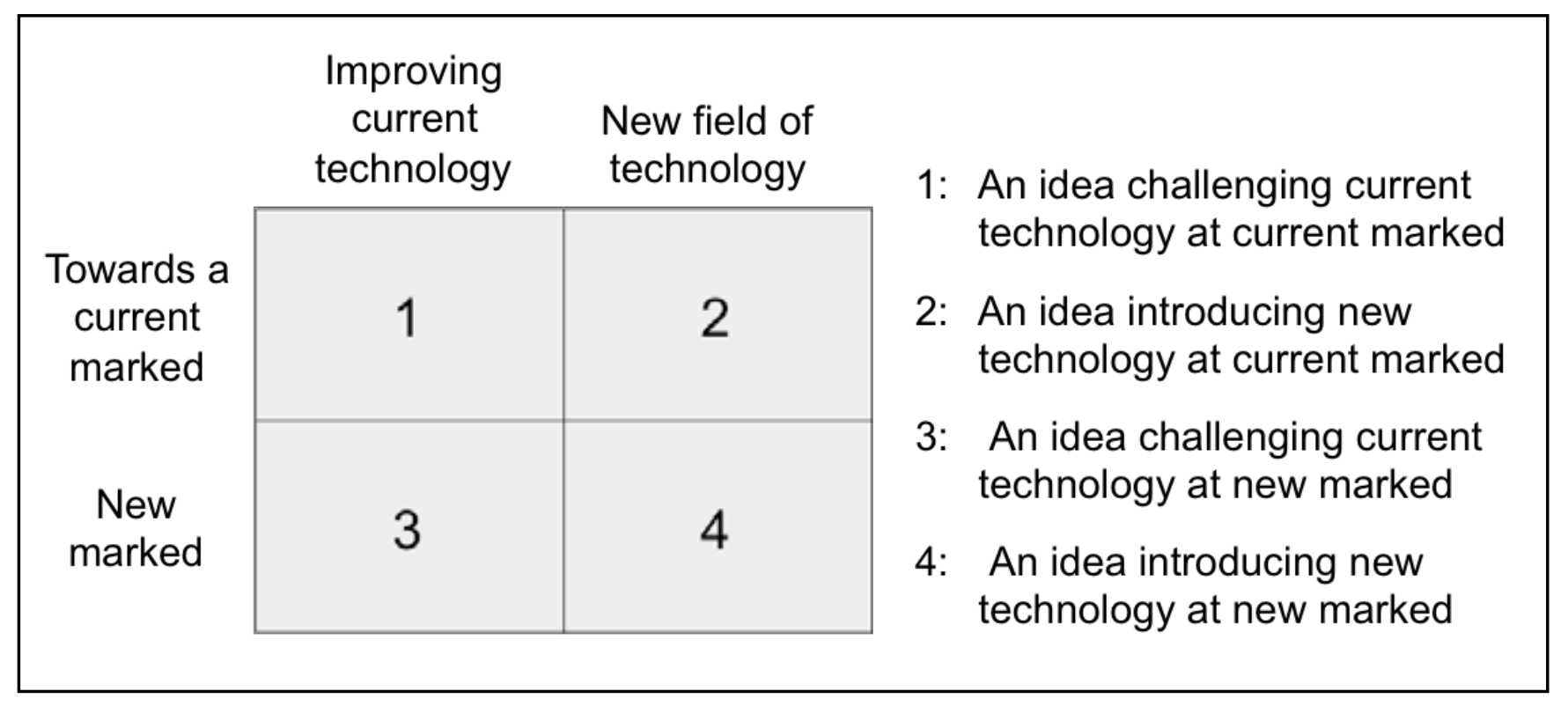

Figure 6. The kind of obstruction the idea meets depends on how the idea challenges existing products and markets. 
An idea that challenges existing technologies on existing markets (sector I) can meet hard obstruction internally, as we saw in for example case 14. Existing investments should pay off and a new product idea concerning an established product/market can meet hard obstruction, although it objectively would be a better product than the existing.

An easier situation is the new technical solution introduced on an existing market (sector 2), complementing the company's product portfolio. Case 2 is one example, where the idea-generating company cooperated with a company working on the market the idea targeted. Internal obstructions were eliminated and the condition for success increased considerably.

Sector 3 is a favorable situation. In the cases 15 and 18 the companies aims for an improved technical solution in a new application, in order to complement their current offerings. This can be used as a pilot test of the new technology or as an exploitation of a technology partially refined towards a new market.

Finally can ideas concerning a new product on a new marked (sector 4) meet major obstacles in being considered outside the company business idea. In case 2 the company initially intercepted the project, but later pursued the idea as a sector 2 idea, through a partnership. This situation can also lead to a spin-off, as in case 6 .

\section{Discussion}

In the previous section, we described observations concerning each component in the framework. In addition, there are observed patterns that concern several of the components. From the cases it is concluded the seven detailed components are necessary but individually not sufficient to maintain a continuous friction free innovation process. All of the parts need to be in order to facilitate an innovation process. In this sense, the issue on supporting innovation is not a question of resource allocation but a question of organization and conditions for organization. An often overlooked element of successful innovation is this climate. As described by Isaksen and Tidd (2006) successful innovation, change and transformation require an environment in which people are ready, willing and able to initiate and sustain change. We have seen that negative dissemination effects can arise if some of the components do not function. For instance a too generous and uncritical financing can erode the quality of the team or lead to an underdeveloped entrepreneur in keeping a non-entrepreneurial inventor as manager.
Although all parts exist, they have different importance and different forms over time in the innovation process. The qualities in the different parts are developed over time and in successful cases is a functional balance developed between these parts; different parts is preventing and enabling in different phases of the innovation process. The idea development is a good example. The fundamental idea and the entrepreneur constitute the core, the idea creates the entrepreneur and the entrepreneur creates the other parts. In the further development plays a critical and risk willing customer a key role. In the framework this is reflected by the third core component: the prototype.

Innovation in established companies has specific characteristics, as also discussed by e $\mathrm{g}$ Griffin et al (2009). Cases showed that there is often a possibility to finance interesting ideas and develop them to a stage where they can be assessed from a technical and marked perspective, even together with a customer. Perhaps the most important asset an established company has when it comes to effective innovation processes is their existing customer base. By this base, ideas can be tested and developed. The obstruction that arises in companies is often internal, as ideas often challenge existing products. Keeping the team from these power disputes has been witnessed as central for the process.

A difference we have seen between the larger company and the free operator/the smaller company is the role of the entrepreneur. For the large company, the entrepreneur becomes more of a project manager, where understanding the internal politics is one of several important abilities.

The innovation process for the free operator is specific in several ways. The inventor and the entrepreneur have a more difficult starting point, especially concerning financing. A 'catch 22' arises if not the entrepreneur or its network can attract a first seed financing. In one case, the entrepreneur solved this dilemma through living very sparse with no economic compensation. Without this initial effort the idea had not been developed further.

The free operator also has a credibility problem while developing the idea with a critical customer. Established companies with existing customer contacts have in this respect an advantage. In specific cases the free operator omitted working with critical, requirement setting customers, perhaps of just this reason. The free operator's need of support within business management has been identified as bigger than for established companies. The 
business angel has shown to contribute with both financing and important knowledge for both free operators and smaller companies.

As we described earlier the fundamental idea is developed over time by continuously iterations with critical customer requirements. In extreme cases, phenomenon were observed that can be described as self-healing, i. e. the idea's development were mutilated, but the momentum of the process "healed" the process. In case 5 the idea showed to be based on entirely incorrect assumptions on technology and market, but while this is concluded, customer relationships were built up and the team was integrated so a new fundamental idea could be created. Another example is case 2 where the idea's development was held back by an incomplete team, but through clear-sighted management the team is complemented with needed competence, in this case from a partner company. In case 14 the idea's development was pursued by complementing the process with critical requirements from a customer. Further examples are the cases 18 and I5 that follow on each other. Once the idea from case 18 showed to be difficult to realize the idea was transformed to case 15 and run in same organization.

This has been an explorative multiple case study with a broad scope. The samples in terms of cases have been diverse in order to gather complementing findings in the entire spanned research space. The aspects to study have also been broad, in order to describe different challenging aspects of the innovation process. In many senses the study raises more questions than it answers. The used analysis framework needs to be tested with larger samples, both from a qualitative perspective as well as a quantitative. Some functions should perhaps be added or subtracted, and the importance and contribution to a successful innovation from the functions need further attention.

In this study the sources of innovation have spanned from individual initiatives on the marked, to small and medium sized companies, to innovation within larger corporations. One specific research direction for the future could be the focus on small and medium sized companies (SME). Managing SME innovation is challenging as both scientific research as well as experiences from the industry indicates that there is a shortage of know-how and "howto" details in the research area (Brook Dobni 2006). A small proportion of innovation research has focused innovations in SMEs, instead focusing large multinational corporations and innovation success stories. Research is also often conducted out of a perspective that focuses on what makes a firm innovative rather than how to make a firm innovative. The need for a more innovative behavior is acute in many SMEs in order to maintain competitive on the global market.

\section{Acknowledgements}

The authors would like to extend our sincere gratitude to Professor Harry Frank, previous research director of $A B B$, who through his lifelong industrial experience have provided us with the analysis framework used in this study. We would also like to extend our sincere gratitude to the consultants at Grufman Reje Management who made this study possible; Anders Grufman, Stefan Frid and Kristina Helles. The financier of the study was VINNOVA - Swedish Governmental Agency for Innovation Systems as well as the Swedish Energy Agency.

\section{References}

ABERNATHY, W., Clark, K. (1985) Mapping the winds of creative destruction. Research Policy, 14, 3-22.

ASSINK, M. (2006) The inhibitors of disruptive innovation capability: a conceptual model. EJIM, 9, 215-233.

BROOK DOBNI, C., (2006), The innovation blueprint, Business Horizon, 49(4), 329-339.

CHARMAZ, K. (2006) Constructing Grounded Theory. Sage Publications.

CHESBOROUGH, H. (2003) Open innovation: The new imperative for creating and profiting form technology. Harvard Business School Press.

CHRISTENSEN, C. (1997) The innovator's dilemma. Harvard Business School Press.

CHRISTENSEN, C., M. Raynor. (2003) The innovator's solution: Creating and sustaining successful growth. Harvard Business School Press.

COLARELLI O'CONNOR, G. (2008) Major innovation as a Dynamic Capability: A systems approach. JPIM, 25, 3I3-330. 
CONWAY, S., Steward, F. (2006) Managing Innovation. Oxford University Press.

CRESWELL, J. W., (2009) Research Design - Qualitative, Quantitative and Mixed Methods Approaches. Sage Publications.

DEEDS, D. L., DeCarolis, D., Coombs, J. (2000) Dynamic capabilities and new product development in high technology ventures: an empirical analysis of new biotechnology firms. Journal of Business Venturing, 15(3), 2II-229.

EISENHARDT K.M., Martin, J. (2000) Dynamic Capabilities: What are they?, Strategic Management Journal, 2I, II05-II2I.

GEORGE, G., Zahra, S.A., Robley Wood, D. (2002) The effects of business-university alliances on innovative output and financial performance: A study of publicly traded biotechnology companies. Journal of Business Venturing, 17: 577-609.

GRIFFIN, A., Price, R. L., Maloney, M. M., Vojak B. A., Sim, E. W., (2009), Voices from the Field: How Exceptional Electronic Industrial Innovators Innovate. JPIM. 26, 222-240.

ISAKSEN, Tidd, J. (2006) Meeting the Innovation Challenge: Leadership for Transformation and Growth. Wiley.

MARINOVA, D., J. Phillimore (2003). Models of innovation. In The international handbook on innovation. Edited by Shavinina, Pp 44-53. Elsevier Science Ltd.

OECD (2005), Guidelines for collecting and interpreting innovation data. 3rd edition - Oslo Manual.

ROGERS, E.M. (2003) Diffusion of Innovations, Free Press.

ROTHWELL, R. (1994), Towards the Fifth-generation Innovation Process. International Marketing Review, II(I):7-3I.

SCHMIDT, G.M. (2004) Low-end and High-end Encroachments for New Products. International Journal of Innovation Management, 8(2): 167-192.

SCHUMPETER, J. (1934), The Theory of Economic Development, Harvard University Press.
TEECE, D. J. (2007) Explicating dynamic capabilities: the nature and micro foundations of (sustainable) enterprise performance. Strategic Management Journal, 28, 1319-1350.

TIDD, J., Bessant, J (2009) Managing Innovation: Integrating technological, market and organizational change, Fourth edition, Wiley.

UTTERBACK, P., Acee, H.J. (2005). Disruptive Technologies: An Expanded View. International Journal of Innovation Management. 9(I): I-I7.

YIN, R. K. (1994) Case Study Research. 2nd edition. SAGE Publications. 
J. Technol. Manag. Innov. 20II,Volume 6, Issue 2 